\title{
水性漆 (水性底漆和水性面漆) 应用于木家具涂饰工艺的研究
}

\section{Study on the Application of Water-based Paint (Waterborne Primer and Waterborne Topcoat) in}

\section{Wood Furniture Finishing Technology}

\section{陈艳海}

Yanhai Chen

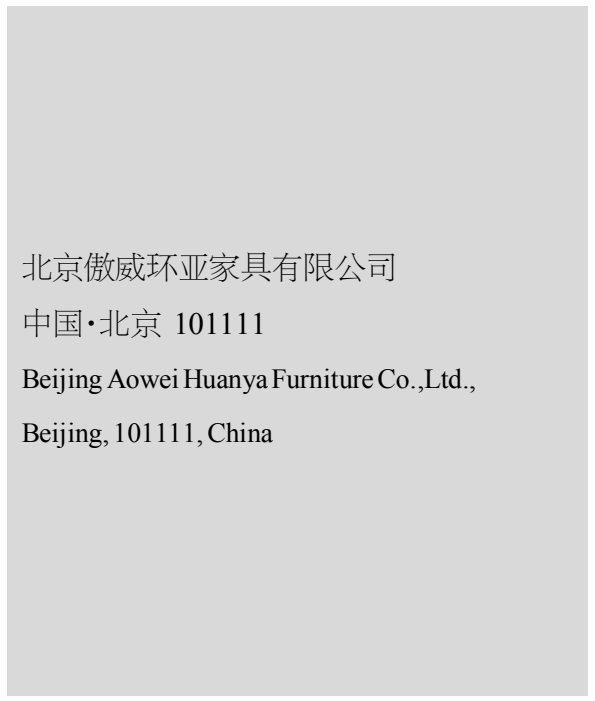

【摘要】随着人们生活水平的提高, 对于生存环境的要求也大大地提高。近几年, 经过不 断地更新和改进, 水性家具涂料的绿色优势再次进入市场, 逐步替代了传统的油性涂料。 文章通过分析目前水性渌的特点、发展现状与存在的问题,介绍了北京傲威环亚家具有限 公司研发的水性漆, 以促进水性漆涂料的发展。

【Abstract】With the improvement of people's living standards, the living environment requirements are also greatly improved. In last few years, through ceaseless renewal and improvement, the green advantage of coating of waterborne furniture enters the market again, replaced traditional oily coating gradually. This paper introduces the water-based paint developed by Beijing Aowei Huanya Furniture Co.,Ltd. through analyzing the characteristics, development status and existing problems of water-based paint, in order to promote the development of water-based paint.

【关键词】水性漆; 高硬度家具; 施工工艺

【Keywords \waterborne paint; high hardness furniture; construction technology

【DOI】10.36012/etr.v1i4.669

\section{1 引言}

在人民生活水平提高的同时，人们对周围的环境也造成 了巨大破坏。中国政府加强了环保理念,要求各行各业的产品 生产必须把保护环境放在第一位。2015 年, 北京发布了最严 格的地方标准:DB11/1202-2015《木质家具制造业大气污染 物排放标准》, 首次提出限制原辅材料中的挥发性有机物含量 标准,以及工艺措施和管理要求, 体现了“源头控制、过程监 管、末端治理”的全过程管控理念。在此背景下,北京傲威环亚 家具有限公司大胆改革,彻底淘汰传统的油性漆, 研究适合自 己的水性漆生产线,为环保做出贡献的同时,也为消费者提供 环保的油漆产品。

\section{2 水性家具漆的优点、发展历史与问题分析}

传统的油性漆是以油脂类作为成膜机制，用有机溶剂进 行稀释或者固化, 溶剂中含有甲醛、苯、二甲苯等多种有害物
质，在工厂施工过程中和消费者使用中会对人体造成严重的 伤害。与油性漆相比, 水性漆则是以水来进行分散、稀释的涂 料, 特点是环保无毒、不易燃烧, 是一种非常环保的涂料。但 是, 水性漆的发展历史并不长, 在施工中还有许多问题亟待解决。 据业内专业人士介绍, 从 20 世纪 40 年代开始, 国际上的水性 涂料技术逐渐发展、成熟, 并将其应用于木器方面。1995 年, 德国开始推广其在欧洲已经成熟的水性木器涂料品牌, 但价 格较高。近几年来, 中国才开始研发水性漆。由于水性漆施工 成本高、涂刷要求高, 对技术和生产工艺等要求更严格, 这是 中国企业在研发水性漆时遇到的最大问题。

\section{3 傲威环保水性漆的研发使用}

为了解决水性漆存在的问题, 北京傲威环亚家具有限公 司加大了研发力度, 专门成立研发小组, 并积极与社会科研机 构合作, 从事水性漆的研发使用。该公司对市场上常用的单组 份丙烯酸水性漆、双组份丙烯酸和聚胺脂水性混合漆、水性光 
固化漆 3 种水性漆进行了研究。经过实践研究, 研发人员发现 单组份水性漆和双组份水性混合漆存在的最大问题是漆膜 软, 硬度达不到家具使用要求, 为此, 公司采用水性光固化漆 作为研究方向。经过不断地研究探索, 公司淘汰了原有的油性 漆生产线，专门找水性漆设备生产厂家量身定制了水性漆生 产线,最终形成了特色的水性漆生产体系。

北京傲威环亚家具有限公司的水性漆特点是：采用全自 动水性光固化漆机械化生产线, 底漆为辊涂水性漆生产线, 面 漆为喷涂生产线。其水性底漆机械化生产线施工工艺如下: 白 坏定厚砂光 $\rightarrow$ 边角抛光 $\rightarrow$ 吸尘 $\rightarrow$ 一辊淢子、二辊压实、三辊水 性底漆 $\rightarrow$ 光固化干燥 $\rightarrow$ 一次水性底漆双辊平面砂光 $\rightarrow$ 吸尘 $\rightarrow$ 二次双辊水性底漆 $\rightarrow$ 二次光固化干燥 $\rightarrow$ 二次水性底漆 $\rightarrow$ 三次 双辊镭射水性底漆 $\rightarrow$ 红外流平 $\rightarrow$ 三次光固化干燥、双辊平面 砂光 $\rightarrow$ 平面底漆精砂光 $\rightarrow$ 异形抛光 $\rightarrow$ 全自动直线磨边 $\rightarrow$ 全自 动多功能精细抛光。

其水性底漆施工工艺有如下关键点：(1)水性漆对于贴木 皮工艺要求严格, 木皮选用 $0.6 \mathrm{~mm}$ 木皮,贴皮用的胶为环保 防水胶,不含甲醛且防水; (2)开机上线前要根据环境温度、湿 度等环境参数对水性漆配比方案进行微调, 实验合格后方可 批量配制; 3水性漆必须用纯净水作为稀释剂, 严禁使用其他 水源作为稀释剂; (4)数码千分尺是生产线上必备的检验测量 工具, 产品上线前必须要进行首件产品调试, 包括设备精度、 砂光机的厚度调整，保证砂光机每次的砂光厚度。

其水性面漆机械化生产线施工工艺如下：水性 UV 漆全
自动喷涂 $\rightarrow$ 红外流平 $\rightarrow$ 光固化干燥 $\rightarrow$ 成品包装。

经过 2 3 年的不断研究，北京傲威环亚家具有限公司的 水性漆生产体系从无到有并逐渐完善。2019 年 3 月,经过检 测，北京傲威环亚家具有限公司水性漆的各项指标均达到并 超过国家标准, 受到国家党政机关及消费者的好评。其检测数 据对比如表 1 所示。

表 1 北京傲威环亚家具有限公司水性漆的 检测数据与国家标准的对比

\begin{tabular}{|c|c|c|c|}
\hline 项目 & 检测数值 & 国标规定数值 & 检测依据 \\
\hline $\begin{array}{l}\text { 甲醛释放量(气 } \\
\text { 候箱法) } \mathrm{mg} / \mathrm{m}^{3}\end{array}$ & $\begin{array}{l}\text { 未检测出 }(\leqslant \\
0.010 \mathrm{mg} / \mathrm{m}^{3} \text { 视 } \\
\text { 为未检测出 })\end{array}$ & $0.124 \mathrm{mg} / \mathrm{m}^{3}$ & $\begin{array}{c}\text { GB } 18580-2017 \\
\text { 《室内装饰装修 } \\
\text { 材料 人造板及其 } \\
\text { 制品中甲醛释放 } \\
\text { 限量》 }\end{array}$ \\
\hline $\begin{array}{c}\text { 总挥发性有机 } \\
\text { 化合物 TVOC } \\
\mathrm{mg} /\left(\mathrm{m}^{2} \cdot \mathrm{h}\right)\end{array}$ & 0.06 & $\leqslant 0.50$ & $\begin{array}{c}\text { HJ 571-2010 } \\
\text { 《环境标志产品 } \\
\text { 技术要求 人造板 } \\
\text { 及其制品》 }\end{array}$ \\
\hline $\begin{array}{c}\text { 铅笔硬度 } \\
\text { (擦伤) }\end{array}$ & $3 \mathrm{H}$ & & $\begin{array}{c}\text { GB/T 6739-2006 } \\
\text { 《色漆和清漆 } \\
\text { 铅笔法测定膜 } \\
\text { 硬度》 }\end{array}$ \\
\hline
\end{tabular}

\section{4 结语}

随着人们生活水平的提高，水性漆在涂装中有广泛的应 用, 不仅使环保家具及木饰面更加美观, 而且大大降低了对人 体和环境的危害, 具有很强的环保功能,无臭、无毒, 且物料的 挥发小。在不久的将来,这种涂料将被广泛应用于建筑材料及 装饰装修领域。 